\title{
Compression force effect on characteristics of loratadine- succinic acid cocrystal prepared by slurry method
}

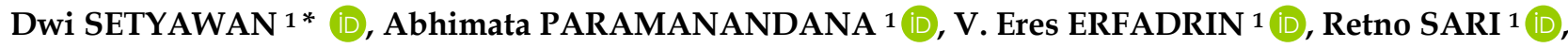 \\ Diajeng Putri PARAMITA 2 (D)
}

1 Department of Pharmaceutics, Faculty of Pharmacy, Universitas Airlangga, Mulyorejo 60115 Surabaya, Indonesia.

2 Department of Pharmaceutical Chemistry, Faculty of Pharmacy, Universitas Airlangga, Mulyorejo 60115 Surabaya, Indonesia.

* Corresponding Author. E-mail: dwisetyawan-90@ff.unair.ac.id (D.S.); Tel. +62-315-933-150.

Received: 24 January 2020 / Revised: 02 April 2020/ Accepted: 09 April 2020

\begin{abstract}
Loratadine belongs to second generation antihistamine (H1) drug and is known to form cocrystal with succinic acid in stoichiometry of 1:1 using slurry method. This study was conducted to further investigate cocrystal phase behavior upon compression. Sample of cocrystal phase was compressed with various compression forces into tablet form on $10 \mathrm{~mm}$ diameter punch. Then, the tablet was characterized for the mechanical properties and physical characterization was conducted using Differential Thermal Analysis (DTA), X-ray Powder Diffraction (XRPD), and Scanning Electron Microscope (SEM). According to tensile strength profile, cocrystal phase showed better mechanical property as it possessed higher tensile strength value compared to loratadine alone. DTA thermograms exhibited succinic acid characteristic peak alongside with endothermic peak of cocrystal phase which were compressed on higher force. It suggests that cocrystal undergoes partial dissociation to the starting components under compression. Powder diffractograms showed reduced intensity of tableted cocrystal compared to powder one for all compression force. SEM photomicrograph observed a loss of particle boundaries of cocrystal upon compression, as sintering phenomena occurred. It is predicted that compression force can influence physical characteristics of cocrystal of loratadine-succinic acid by driving dissociation and sintering phenomena.
\end{abstract}

KEYWORDS: Cocrystal; compression force; loratadine; physical characterization; succinic acid.

\section{INTRODUCTION}

Loratadine is a second generation of $\mathrm{H} 1$ histamine antagonist drug form tricyclic piperidine derivative that commonly commercialized in tablet dosage form [1]. Loratadine has $\mathrm{pH}$-dependent solubility profile in water that the higher the $\mathrm{pH}$, the lower the solubility is. As suffering from low solubility but high membrane permeability, loratadine is classified as Class II compound in Biopharmaceutics Classification System (BCS). In addition, low solubility of loratadine will be problematic in the dissolution behavior that subsequently affects absorption and bioavailability of loratadine itself [2]. Many techniques have been approached to modify loratadine's solubility with positive results, including nanoparticle, solid lipid microparticle, solid dispersion, complex inclusion with cyclodextrin, and cocrystal [3-7].

Cocrystal is described as crystalline phase assembled from two or more different molecules via noncovalent bond. Cocrystal engineering is emerging as potential technique to overcome the problems related to poor solubility and poor physicochemical properties of a drug, whilst maintaining acceptable stability [8, 9]. In our previous study, loratadine has been physically modified into cocrystal supermolecule with succinic acid as coformer [10]. Loratadine has two functional groups that can act as hydrogen bond acceptor in cocrystal interaction, those are carbonyl group and aromatic nitrogen. Succinic acid contains two carboxylic groups in its structure that take role as both hydrogen bond donor and acceptor, so that it was chosen for loratadine cocrystal formation. Cocrystallization was performed using slurry method with methanol as the added solvent. Physical characterization showed that cocrystal of loratadine-succinic acid was formed in 1:1 stoichiometry. Hydrogen bonding was characterized between the carboxyl group of succinic acid and the carbonyl group of loratadine in $\mathrm{O}-\mathrm{H} . . . \mathrm{O}=\mathrm{C}$ fashion $[10,11,12]$, as illustrated in Figure 1 (the illustration was produced using Hyperchem 8.0 (Hypercube Inc., USA)).

How to cite this article: Setyawan D, Paramandana A, Erfadrin VE, Sari R, Paramita DP. Compression force effect on characteristics of loratadinesuccinic acid cocrystal prepared by slurry method. J Res Pharm. 2020; 24(3): 410-415. 
It has been known in the previous study that cocrystal formation with succinic acid improved aqueous solubility of loratadine [10]. Therefore, this research was conducted to further characterize cocrystal phase properties of loratadine and succinic acid under compression force. It is necessary to thoroughly understand the behavior of loratadine cocrystal upon compression, especially when we deal with tablet dosage form because it will dictate formulation and manufacturing process. Furthermore, compression introduces mechanical energy into compressed powder that can induce interaction [13] but it can work the other way around, as for cocrystal case, the breakage of hydrogen bonding between loratadine and succinic acid and potentially alters cocrystal characteristics. Cocrystal phase was compressed with various compression forces to construct tensile strength curve, then characterized using differential thermal analysis (DTA), X-ray powder diffraction (XRPD), and scanning electron microscope (SEM).

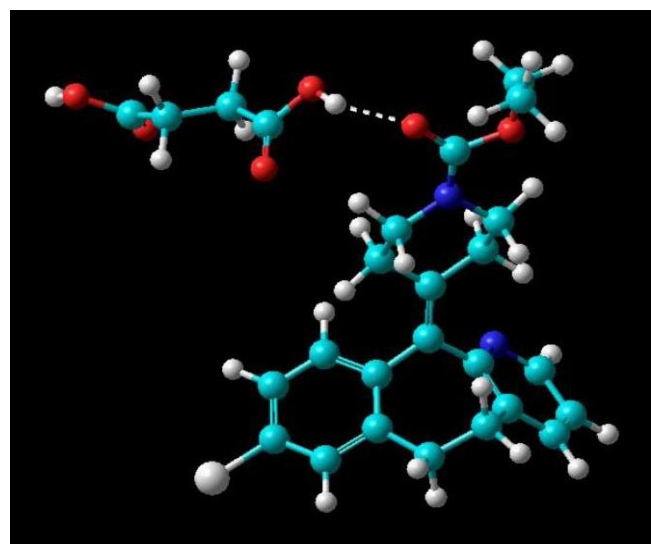

Figure 1. Illustration of $\mathrm{O}-\mathrm{H} . . . \mathrm{O}=\mathrm{C}$ hydrogen bonding involved in loratadine-succinic acid cocrystal.

\section{RESULTS AND DISCUSSION}

\subsection{Mechanical property}

Mechanical property of loratadine and loratadine-succinic acid cocrystal is described as tensile strength curve shown in Figure 2. Tensile strength is an important parameter in tablet dosage form production as it represents the ability of a component or mixture of components to withstand the compression force applied and form compacted tablet without failure [14]. Both samples exhibited the same trend, that tensile strength increased with higher compression force. However, loratadine reached the highest value of tensile strength $\left(2.55 \pm 0.17 \mathrm{~N} / \mathrm{mm}^{2}\right)$ at compression force of $15 \mathrm{kN}$ before decreasing at $20 \mathrm{kN}$. In addition, tableted loratadine experienced capping after compression at $20 \mathrm{kN}$. This phenomenon is called over-compaction because of elastic deformation of loratadine in higher compression force that no longer able to maintain compacted form [15]. Cocrystal of loratadine-succinic acid interestingly showed higher tensile strength compared to loratadine alone and no over-compaction profile. It means that cocrystal phase possesses better ability to be compacted into good tablet within wide range of compression force. Furthermore, it has been proposed that pharmaceutical tablet should have minimum tensile strength of $2 \mathrm{~N} / \mathrm{mm}^{2}$ for ensuring integrity [16], so that cocrystal of loratadine-succinic acid suggests good tabletability with minor or no problem at all.

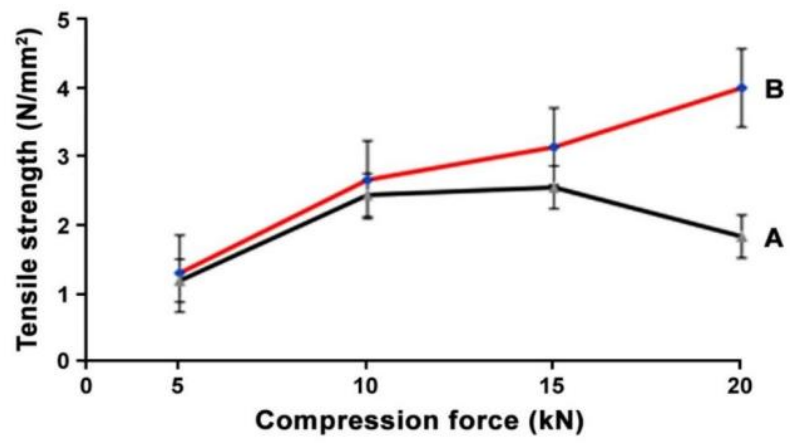

Figure 2. Tensile strength curve of (A) loratadine and (B) loratadine-succinic acid cocrystal. 


\subsection{Thermal analysis}

DTA thermograms of loratadine, succinic acid, cocrystal phase, both powder and tableted samples, are presented in Figure 3. Loratadine exhibited single endothermic peak of melting event at $136.4^{\circ} \mathrm{C}$ [17]. Succinic acid exhibits two endothermic peaks at 190 and $250^{\circ} \mathrm{C}$ attributed to melting and evaporation event, respectively [18]. Cocrystal phase exhibited specific endothermic peak at $110.0^{\circ} \mathrm{C}$, corresponding to melting event [10]. The same DTA profile was obtained from tableted cocrystal that compressed at 5 and $10 \mathrm{kN}$ compression force. Meanwhile, tableted cocrystal from higher compression force showed the second endothermic peak near $260^{\circ} \mathrm{C}$. Our premilinary study with physical mixture sample also showed the second endothermic peak of succinic acid at around $260^{\circ} \mathrm{C}$. Reappearance of the starting component peak is indication of breakage of hydrogen bonding employed in cocrystal lattice. It is quite safe to say that dissociation between loratadine and succinic acid occurs in rather small fashion, noticing endothermic peak of cocrystal phase is there as well. Hydrogen bond is kind of weak bond that can break easily upon energy exposure [19]. Since energy load does not distribute evenly throughout the tablet and usually concentrated on the area where powder and punch contact [20], dissociation of cocrystal possibly is manifested on tablet surfaces.

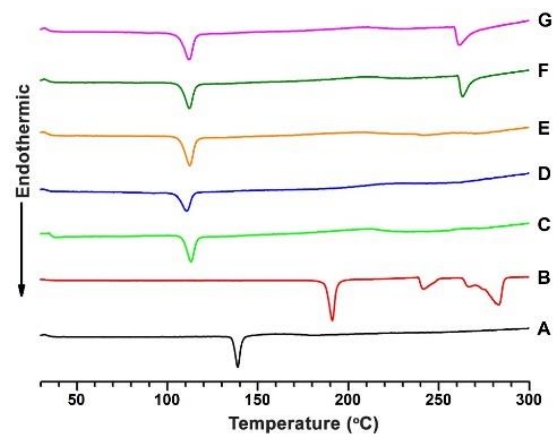

Figure 3. DTA thermogram of (A) loratadine, (B) succinic acid, (C) cocrystal phase powder and tableted ones at compression force of (D) 5, (E) 10, (F) 15, and (G) $20 \mathrm{kN}$.

\subsection{X-ray diffraction}

Behavior of loratadine-succinic acid cocrystal upon compression was analyzed further with XRPD. Figure 4 displays $\mathrm{X}$-ray diffractograms of loratadine, succinic acid, cocrystal phase powder and tableted ones with various compression forces. Cocrystal phase was characterized with distinctive diffraction peak at $2 \theta=$ $9.83,11.97,21.15$, and $28.33^{\circ}$, in comparison to the starting components [10]. Compression does not really affect $2 \theta$ value, but peak intensity instead. A decrease in intensity was observed on diffractogram of all tableted samples. It suggests that compression may decrease crystallinity of the cocrystal. Peak intensity decrease also possibly relates to dissociation of cocrystal due to compression. However, we assume that decrease in peak intensity cannot be explained by dissociation phenomenon alone since dissociation is predicted to locally occur on the tablet surface. Inadequate amount of the starting components also explains why peak loss or change in diffraction profile is not observed when change in crystal lattice is supposed to occur [21].

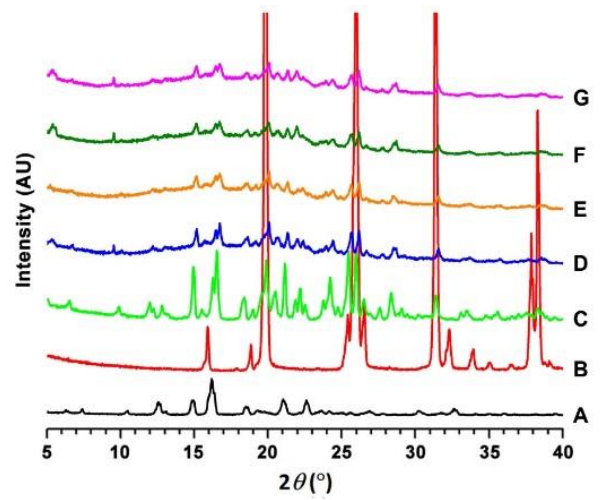

Figure 4. Powder diffractogram of (A) loratadine, (B) succinic acid, (C) cocrystal phase powder and tableted ones at compression force of (D) 5, (E) 10, (F) 15, and (G) $20 \mathrm{kN}$. 


\subsection{SEM photographs}

Morphology evaluation of loratadine-succinic acid cocrystal was conducted under SEM observation. Figure 5 illustrates morphology of crystal habit of loratadine, succinic acid, and cocrystal phase and tablet surface of cocrystal that compressed at $20 \mathrm{kN}$, the highest compression force used in this research. Cocrystal phase showed different habit compared to needle-shape of loratadine or layered-structure of succinic acid, with small varying prismatic shape and was obtained as aggregate particles, which is a common thing when one utilizes milling for cocrystallization [10, 22]. Worth to note, tableted cocrystal had very smooth surface, boundaries between particles also mostly disappeared. Loss of particle boundary occurs as a result of incorporation of adjacent particles due to mechanical energy. This phenomenon is called sintering [23]. Sintering upon mechanical energy can be explained by the impact of heat generated from particle friction during compression. The lower-melting component can melt due to the heat and further causes particle rearrangement. Once the pressure is removed (as well as the heat), solidification occurs to form solid bonds between particles. Numbers of active component have been reported to undergo sintering under compression [24, 25]. It can affect tablet quality as sintering generally retard dissolution and drug release [26].

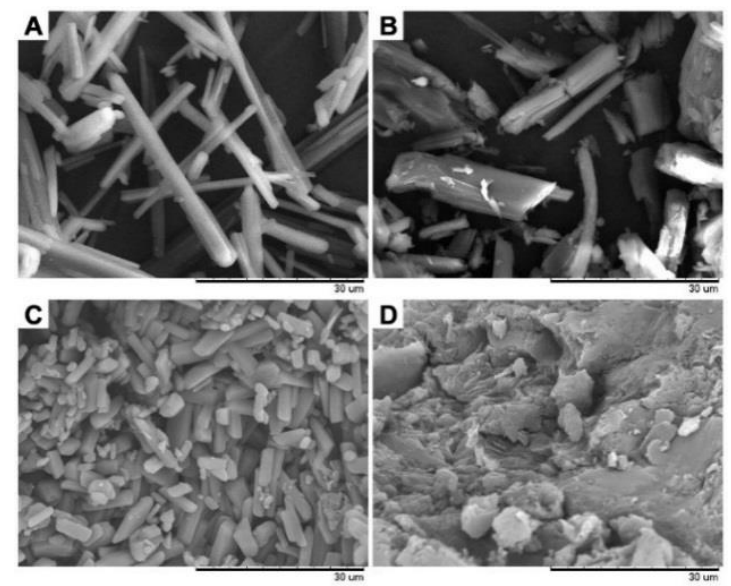

Figure 5. SEM photograph of (A) loratadine, (B) succinic acid, (C) cocrystal phase powder, and (D) tableted one at magnification of 2500 .

\section{CONCLUSION}

Cocrystal of loratadine-succinic acid shows better tabletability profile compared to loratadine alone and possesses good mechanical property toward capping issue. However, cocrystal phase demonstrates a change in characteristics during compression, especially at high compression force. Compression leads to partial dissociation of hydrogen bonding that holds loratadine and succinic acid together in crystal lattice. Compression also decreases crystallinity of the cocrystal and the latter undergoes sintering as well. Thus, it is concluded that formulation into tablet dosage form may alters physical characteristics of loratadine-succinic acid cocrystal, especially when compressed at higher compression force.

\section{MATERIALS AND METHODS}

\subsection{Materials}

Loratadine was purchased from Vasudha Pharma Chem Limited, India. Other material used were succinic acid and analytical grade methanol (both from Merck, Germany).

\subsection{Preparation of loratadine-succinic acid cocrystal}

Cocrystal of loratadine and succinic acid was prepared using slurry method in a high energy milling apparatus (LIPI, Indonesia). Each component was weighed equimolarly according to stoichiometry of 1:1. Methanol was used as solvent for slurry process which added as much as $36 \%(v / w)$. Cocrystal components, methanol, and $6.3 \mathrm{~mm}$ grinding balls (approximately powder weight) were added into the grinding jar. The mill was run for 30 minutes with speed of $1000 \mathrm{rpm}$. The remaining methanol was evaporated at room temperature to obtain cocrystal solid that was sieved through mesh no. 50 before storage in desiccator for further examination. 


\subsection{Mechanical property}

Natoli RD10A-1520 tablet press (USA) with $10 \mathrm{~mm}$ diameter punch was used to study mechanical property of loratadine and its cocrystal phase. Tableted samples were obtained by compressing $300 \mathrm{mg}$ of loratadine or loratadine-succinic acid cocrystal alone under different compression force from 5 to $20 \mathrm{kN}$. Inner wall of die and punch surface were coated with magnesium stearate for lubrication and ease of ejection. Compressed tablet was stored in desiccator for 1 day for elastic recovery. Measurement was conducted for tablet thickness and diameter as well as tablet hardness using Erweka TB 24 hardness tester (Germany). Calculation of tensile strength $(\sigma)\left(\mathrm{N} / \mathrm{mm}^{2}\right)$ used the following equation:

$$
\sigma=\frac{2 F}{\pi D t}
$$

where $\mathrm{F}$ is hardness $(\mathrm{N}), \mathrm{D}$ and $\mathrm{t}$ are tablet diameter and thickness, respectively, in $\mathrm{mm}$.

\subsection{Thermal analysis}

Thermal analysis was carried out using Mettler Toledo FP85 TA Cell differential thermal analyser (DTA) (Switzerland). About 2 to $3 \mathrm{mg}$ of sample was placed in sealed aluminium crucible for scanning in heating rate of $5^{\circ} \mathrm{C} / \mathrm{min}$ and temperature range of $30-300^{\circ} \mathrm{C}$. For tableted samples, analysis used small chunk from tablet edge.

\subsection{X-ray powder diffraction (XRPD)}

XRPD analysis was conducted with Phillips X'pert-3 diffractometer (Netherland) utilized Cu radiation. Sample was placed in the sample holder for scanning over $2 \theta$ range of $5-40^{\circ}$, with step size of $0.017^{\circ}$ and divergence slit size of $0.87^{\circ}$. Electricity was set at $40 \mathrm{kV}$ and $30 \mathrm{~mA}$. For tableted sample, analysis was performed on a half piece of tablet.

\subsection{Scanning electron microscope (SEM)}

Photomicrographs were collected on Hitachi TM 3000 Tabletop scanning electron microscope (SEM) (Japan). Morphology of each sample was captured at magnification of 2500.

Acknowledgements: Authors acknowledge the Ministry of Research, Technology, and Higher Education for funding our research through grant of Penelitian Dasar Unggulan Perguruan Tinggi (PDUPT) No. 623/UN3.14/LT/2019.

Author contributions: Concept - D.S.; Design - D.S., D.P.P.; Supervision - D.S., R.S.; Resources - E.E., R.S.; Materials A.P., E.E.; Data Collection and/or Processing - E.E.; Analysis and/or Interpretation - D.S., A.P., E.E., D.P.P.; Literature Search - E.E., D.P.P.; Writing - D.P.P.; Critical Reviews - D.S., A.P., E.E., R.S., D.P.P.

Conflict of interest statement: The authors declared no conflict of interest.

\section{REFERENCES}

[1] Vlaia L, Coneac G, Olariu I, Mut AM, Anghel DF, Maxim ME, Maxim ME, Şaramet G, Mitu M, Lupuliasa D, Vlaia V. Loratadine-loaded Microemulsions for Topical Application. Formulation, physicochemical characterization and in vitro drug release evaluation. Farmacia. 2017; 65(6): 851-861.

[2] Khan MZ, Rausl D, Zanoski R, Zidar S, Mikulcić JH, Krizmanić L, Eskinja M, Mildner B, Knezević Z. Classification of Loratadine Based on the Biopharmaceutics Drug Classification Concept and Possible in Vitro-in Vivo Correlation. Biol Pharm Bull. 2004; 27(10): 1630-1635. [CrossRef]

[3] Alshweiat A, Katona G, Csóka I, Ambrus R. Design and characterization of loratadine nanosuspension prepared by ultrasonic-assisted precipitation. Eur J Pharm Sci. 2018; 122: 94-104. [CrossRef]

[4] Milak S, Medlicott N, Tucker IG. Solid lipid microparticles containing loratadine prepared using a Micromixer. J Microencapsul. 2006; 23(8): 823-831. [CrossRef]

[5] Frizon F, Eloy JO, Donaduzzi CM, Mitsui ML, Marchetti JM. Dissolution rate enhancement of loratadine in polyvinylpyrrolidone K-30 solid dispersions by solvent methods. Powder Technol. 2013; 235: 532-539. [CrossRef] 
[6] Omar L. El-Barghouthi MI, Masoud NA, Abdoh AA, Al Omari MM, Zughul MB, Badwan AA. Inclusion complexation of loratadine with natural and modified cyclodextrins: phase solubility and thermodynamic studies. J. Solution Chem. 2007; 36(5): 605-616. [CrossRef]

[7] Setyawan D, Pravianti ERD, Pratiwi KD, Isadiartuti D, Paramita DP. Cocrystallization of loratadine with succinic acid using neat grinding method (September 30, 2019). Proceedings of International Conference on Applied Pharmaceutical Sciences (ICoAPS) 2018. [CrossRef]

[8] Setyawan D, Permata AS, Zainul A, Lestari MLAD. Improvement in Vitro Dissolution Rate of Quercetin Using Cocrystallization of Quercetin-Malonic Acid. Indones J Chem. 2018; 18(3): 531-536. [CrossRef]

[9] Gadade DD, Pekamwar SS, Lahoti SR, Patni SD, Sarode MC. Cocrystallization of etodolac: prediction of cocrystallization, synthesis, solid state characterization and in vitro drug release. Marmara Pharm J. 2017; 21: 78-88.

[10] Paramanandana A, Setyawan D. Loratadine-Succinic Acid Cocrystals Physical Modification Made Using Slurry Method. Proceeding of the 2nd International Conference on Medicine and Health Sciences; 2018 Nov 30-Des 1; Jember, Indonesia. Universitas Jember, 2018.

[11] Duggirala NK, Perry ML, Almarsson Ö, Zaworotko MJ. Pharmaceutical cocrystals: along the path to improved medicines. Chem Commun (Camb). 2016; 52(4): 640-655. [CrossRef]

[12] Qiao N, Li M, Schlindwein W, Malek N, Davies A, Trappitt G. Pharmaceutical cocrystals: an overview. Int J Pharm. 2011; 419(1-2): 1-11. [CrossRef]

[13] Hosaka S, Sadoshima T, Sato M, Hamada C, Takahashi Y, Kitamori N. Effects of compression on the interaction between 1,4-dihydropyridine compounds and lactose monohydrate (II): differences in powder properties of 1,4dihydropyridine compounds. Chem Pharm Bull. 2007; 55(5): 793-795. [CrossRef]

[14] Hayashi Y, Oishi T, Shirotori K, Marumo Y, Kosugi A, Kumada S, Hirai D, Takayama K, Onuki Y. Modeling of quantitative relationships between physicochemical properties of active pharmaceutical ingredients and tensile strength of tablets using a boosted tree. Drug Dev Ind Pharm. 2018; 44(7): 1090-1098. [CrossRef]

[15] Ainurofiq A, Mauludin R, Mudhakir D, Umeda D, Soewandhi SN, Putra OD. Improving mechanical properties of desloratadine via multicomponent crystal formation. Eur J Pharm Sci. 2018; 111: 65-72. [CrossRef]

[16] Perumalla SR, Sun CC. Enabling tablet product development of 5- fluorocytosine through integrated crystal and particle engineering. J Pharm Sci. 2014; 103(4): 1126-1132. [CrossRef]

[17] Ramos LA, Cavalheiro ÉTG. Thermal behavior of loratadine. J Therm Anal Calorim. 2007; 87: 831-834. [CrossRef]

[18] Caires FJ, Lima LS, Carvalho CT, Ionashiro M. Thermal behaviour of succinic acid, sodium succinate and its compounds with some bivalent transition metal ions. Thermochim Acta. 2010; 500(1-2): 6-12. [CrossRef]

[19] Ober CA, Gupta RB. Formation of itraconazole-succinic acid cocrystals by gas antisolvent cocrystallization. AAPS PharmSciTech. 2012; 13(4): 1396-1406. [CrossRef]

[20] Sinka IC, Cunningham JC, Zavaliangos A. Analysis of tablet compaction. II. Finite element analysis of density distributions in convex tablets. J Pharm Sci. 2004; 93(8): 2040-2053. [CrossRef]

[21] Athiyah U, Kusuma PA, Tutik T, Lestari MLAD, Isadiartuti D, Paramita DP, Setyawan D. Crystal engineering of quercetin by liquid assisted grinding method. J Teknol. 2019; 81(1): 1-7. [CrossRef]

[22] Rahman Z, Agarabi C, Zidan AR, Khan SR, Khan MA. Physico-mechanical and Stability Evaluation of Carbamazepine Cocrystal with Nicotinamide. AAPS PharmSciTech. 2011; 12(2): 693-704. [CrossRef]

[23] Rao MRP, Ranpise AA, Thanki KC, Borate SG, Parikh GN. Effect of Processing and Sintering on Controlled Release Wax Matrix Tablets of Ketorolac Tromethamine. Indian J Pharm Sci. 2009; 71(5): 538-544. [CrossRef]

[24] Setyawan D, Isadiartuti D, Betari SD, Paramita DP. Physical Characterization of Ibuprofen-Stearic Acid Binary Mixture Due to Compression Force. Indones J Pharm. 2016; 27(1): 28-34. [CrossRef]

[25] Setyawan D, Sumirtapura YC, Soewandhi SN, Hadi Tj D. Characterization of Physical Properties and Dissolution Rate of Binary Systems Erythromycin Stearate-Microcrystalline Cellulose and Spray Dried Lactose Due to Compression Forces. Int J Pharm Pharm Sci. 2012; 4(1): 652-657.

[26] Singh R, Poddar SS, Chivate A. Sintering of Wax for Controlling Release from Pellets. AAPS PharmSciTech. 2007; 8(3): E1-E9. [CrossRef] 